\title{
Structural Data, Linear and Nonlinear Optical Properties of Some Cyclic Phosphazenes: A Theoretical Investigation
}

\author{
D. Hadji, ${ }^{\mathrm{a}, \mathrm{b},}$ and A. Rahmouni ${ }^{\mathrm{b}}$ \\ ${ }^{a}$ Département de Chimie, Facultés des Sciences Exactes, Université de Sidi-Bel-Abbès, Algérie \\ ${ }^{b}$ Département de Chimie, Facultés des Sciences, Université Docteur M. Tahar de Saïda, BP.138, Algérie \\ ${ }^{a b}$ Laboratoire de Modélisation et Méthodes de Calcul, Université Docteur M. Tahar de Saïda, BP.138, Algérie
}

\begin{abstract}
We report ab initio and DFT calculation of structural data, dipole moment, diagonal vibrational and electronic contributions to polarizability, vibrational and electronic contributions to first hyperpolarizability of some cyclic phosphazenes. The electronic structure of substituted cyclic phosphazenes has been investigated using Hartree-Fock and density functional theory. The vibrational and electronic contributions to polarizabilities and first hyperpolarizability of these molecules were calculated with HF method, and different DFT levels used the traditional B3LYP and PBE functional and the long-range corrected functional like Coulomb-attenuating method CAM-B3LYP, LC-BLYP and wB97XD used different basis sets. These cyclic phosphazenes adopts a planar structure. The study reveals that the cyclic phosphazenes derivatives have large vibrational contribution to static first hyperpolarizability values. The results obtained from this work will provide into the electronic properties of this important class of inorganic polymers.
\end{abstract}

Keywords: Mean polarizability, polarizability anisotropy, vibrational and electronic polarizability, vibrational and electronic first hyperpolarizability.

\section{INTRODUCTION}

Cyclicphosphazene studies in this paper are inorganic compound with the formula $\left(\mathrm{NPX}_{2}\right)_{n}$ with $\mathrm{n}=3$ and $\mathrm{X}=\mathrm{H}, \mathrm{Br}, \mathrm{Cl}$ and $\mathrm{F}$. These molecules have a cyclic backbone consisting of alternating phosphorus and nitrogen atoms. The chemistry of the phosphazenes goes back to 1834 when Liebig and Wöhler isolated a small of an unidentified crystalline product from the reaction of ammonia and phosphorus pentachloride [1]. The first phosphazene which was synthesized and isolated, was $\left(\mathrm{NPCl}_{2}\right)_{3}$ [2]. In 1895, Stokes suggested a cyclic structure for this compound [3]. The cyclic phosphazenes are of interest to both theoretical and experimental chemists. For example, a new class of thermo-sensitive cyclotriphosphazenes has been first synthesized recently by stepwise substitution of hexachlorocyclotriphosphazene $\left(\mathrm{NPCl}_{2}\right)_{3} \quad$ [4], with alkoxypoly (ethyleneglycol) and amino acid esters. Phosphazenes materials with interesting properties, for example, they exhibit fire-retardant properties, have high refractive indices, and might find application in nonlinear optics, as ferro-electric materials, as liquid crystals or as photoactive materials [5-11]. They also possess a number of characteristics such as biomedical properties and applications due to their strong antitumor activity. Magnetic properties for the new complexes are prepared in one step

*Address correspondence to this author at the Département de Chimie, Facultés des Sciences Exactes, Université de Sidi-Bel-Abbès, Algérie; Tel: +213792899031; Fax: +21348507192; E-mail: hadji120780@yahoo.fr functionalization; coordination used cyclic phosphazene $\mathrm{N}_{3} \mathrm{P}_{3} \mathrm{Cl}_{6}$ by Spodine et al. [12]. Biologically; important substrates such as anti-cancer agents, insect chemosterilants, pesticides, fertilizers, and supports for catalysts, dyes, and crown ether-phase transfer catalysts for nucleophilic substitution reactions. Application for cyclic and polymeric phosphazene as solid state template for the formation of $\mathrm{RuO}_{2}$ nanoparticles such as the work of Spodine et al. [13], and in application of Boratophosphazene like synthesis of Borazine-phosphazene hybrid cations such as the work of Rheingold et al. [14].

For some systems and processes the electronic and vibrational properties are even more important than the corresponding electronic ones, together both contributions govern nonlinear optical NLO behavior. A large number of the vibrational calculations have proceeded with theoretical calculation like $\operatorname{HF}[15,16]$, DFT [17] and MP2 [18] last years.

The chemical structure of these cyclic phosphazenes studies in this work are showed in (Figure 1).

\section{COMPUTATIONAL DETAILS AND METHODS}

In this section we will present only brief description of the calculation methods used to calculate electronic and vibrational contributions to static polarizability and electronic and vibrational contributions to static first hyperpolarizabilities. The reader unfamiliar with the applied methods may refer to the vast literature on the 


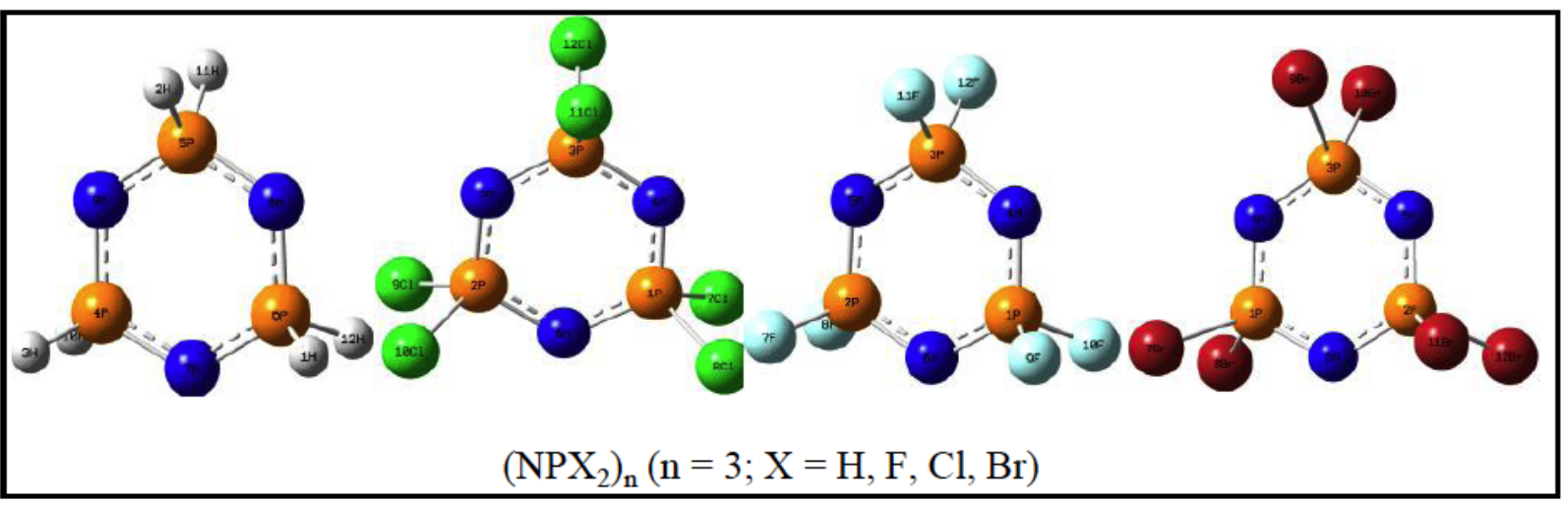

Figure 1: Chemical structure of these cyclic phosphazenes studies in this work.

subject. Analytical calculation of electrical properties are not carry out in this work, Interested on the static properties.

In the presence of a uniform electric field, the total energy of molecule can be expressed as a Taylor series:

$\mathrm{E}(\mathrm{F})=\mathrm{E}(0)-\mu_{\mathrm{i}} \mathrm{F}_{\mathrm{i}}-\frac{1}{2 !} \alpha_{\mathrm{ij}} \mathrm{F}_{\mathrm{i}} \mathrm{F}_{\mathrm{j}}$

$-\frac{1}{3 !} \beta_{\mathrm{ijk}} \mathrm{F}_{\mathrm{i}} \mathrm{F}_{\mathrm{j}} \mathrm{F}_{\mathrm{k}}-\frac{1}{4 !} \gamma_{\mathrm{ijk} k} \mathrm{~F}_{\mathrm{i}} \mathrm{F}_{\mathrm{j}} \mathrm{F}_{\mathrm{k}} \mathrm{F}_{1} \ldots$

$\mu, \alpha$, and $\beta$ dipole moment, polarizability, and first to $\mathrm{n}^{\text {th }}$ order hyperpolarizability, respectively.

Equation (1) used for calculations of electric dipole (hyper) polarizabilities. Within the Born Oppenheimer approximation and, for a non-rotating and nontranslating molecule, the hyperpolarizability can be split into electronic and vibrational contributions, a number of research groups have focused their attention recently on the evaluation of vibrational hyperpolarizabilities [19].

$\mathrm{P}=\mathrm{P}^{\text {ele }}+\mathrm{P}^{\mathrm{vib}}$

\subsection{Electronic Diagonal Polarizabilities and Electronic Static First Hyperpolarizabilities}

For the calculation of electronic contributions to static firs thyperpolarizabilities, we followed the procedure outlined by Kurtz et al. [20, 21] and used equation (1) for numerical differentiation of the total energy of the molecular system with respect to the electric field. Our calculations were performed using $a b$ initio and density functional theory (DFT) methods. The performances of traditional and novel long-range corrected DFT levels were explored. Long-range corrected DFT functionals can be competitive to traditional DFT functionals and $a b$ initio methods to calculate linear and nonlinear response electric properties, owing to accuracy and minor computational demand. Indeed, recent studies have demonstrated that long-range corrected DFT methods are largely superior to traditional functionals, with results comparable to ab initio levels in predicting (hyper) polarizabilities [22-30]. In the case of orientationally invariant hyperpolarizabilities [31],

$$
\begin{aligned}
& \bar{\alpha}=\frac{1}{3} \sum_{\mathrm{i}=x, y, z} \alpha_{\mathrm{ii}} \\
& \bar{\beta}=\sum_{\mathrm{i}=x, y, z} \frac{\mu_{\mathrm{i}} \beta_{\mathrm{i}}}{|\mu|}
\end{aligned}
$$

where

$$
\beta_{\mathrm{i}}=\frac{1}{5} \sum_{\mathrm{j}=\mathrm{x}, \mathrm{y}, \mathrm{z}}\left(\beta_{\mathrm{ijj}}+\beta_{\mathrm{jij}}+\beta_{\mathrm{jij}}\right)
$$

The value of the field amplitude (equal to $0.001 \mathrm{a} \mathrm{u}$ ) was assumed. In the case of diagonal tensor elements; the Romberg differentiation procedure was employed [32]. The Romberg procedure was also used to remove the higher order hyperpolarizability contaminations.

The diagonal components were determined according to equation (5) from second-order derivatives of the energy with respect to the relevant components of the field, using a second-order polynomial least square shift over energies obtained after embedding the target of interest in homogenous electric fields in the $x, y$ and $z$ directions.

\subsection{Diagonal Vibrational Polarizabilities and Vibrational First Hyperpolarizabilities}

The mean polarizabilities value $\langle\alpha\rangle=\frac{1}{3}\left(\alpha_{x x}+\alpha_{y y}+\alpha_{z z}\right)$ is usually determined from the refractive index or from dielectric measurements [33], while vibrational 
polarizabilities $\alpha_{\mathrm{v}}$ can be obtained from infrared intensities [34, 35]. In this work, the vibrational contribution $\alpha$ to be evaluated under the double harmonic oscillator approximation with the sum-overmodes expression [36].

$\alpha_{i j}^{v}=\sum_{a}^{3 N-6} \frac{\left(\frac{\partial \mu_{i}}{\partial Q_{a}}\right)_{0}\left(\frac{\partial \mu_{j}}{\partial Q_{a}}\right)_{0}}{\omega_{a}^{2}}$

Where $\omega_{\mathrm{a}}$ is the circular vibrational frequency of the $\mathrm{n}^{\text {th }}$ normal mode $\mathrm{Q}_{\mathrm{a}}$ and $\frac{\partial \mu_{\mathrm{i}}}{\partial \mathrm{Q}_{\mathrm{a}}}$ is the partial derivative of the i-component of $\mu$ with respect to $\mathrm{Q}_{a}$ evaluated at the equilibrium geometry.

A perturbation treatment of dynamic vibrational hyperpolarizabilities has been given by Bishop and Kirtman (BK) [37, 38]. This treatment is based on the general sum-over-states (SOS) formulas [39] for the total hyperpolarizability given in terms of vibronic energies and dipole moment matrix elements. Then the vibrational and electronic contributions are separated by applying a canonical or clamped nucleus approximation [40].

The vibrational first hyperpolarizability:

$\beta_{\mathrm{ijk}}^{\mathrm{v}}=[\mu \alpha]^{0,0}=$

$\sum_{\xi}\left(\frac{1}{\omega_{\xi}^{2}}\right)\left[\left(\frac{\partial \mu_{\mathrm{i}}}{\partial \mathrm{Q}_{\xi}}\right)_{0}\left(\frac{\partial \alpha_{\mathrm{jk}}}{\partial \mathrm{Q}_{\xi}}\right)_{0}+\left(\frac{\partial \mu_{\mathrm{j}}}{\partial \mathrm{Q}_{\xi}}\right)_{0}+\left(\frac{\partial \mu_{\mathrm{k}}}{\partial \mathrm{Q}_{\xi}}\right)_{0}\left(\frac{\partial \alpha_{\mathrm{ij}}}{\partial \mathrm{Q}_{\xi}}\right)_{0}\right]$

Where $Q_{\zeta}$ denotes $\zeta^{\text {th }}$ normal vibrational coordinate of frequency $\omega_{\zeta}$, and $\frac{\partial \mu_{\mathrm{i}}}{\partial \mathrm{Q}_{\xi}}$ and $\frac{\partial \alpha_{\mathrm{jk}}}{\partial \mathrm{Q}_{\xi}}$ are the derivatives of the molecular dipole moment and polarizability with respect to normal coordinate $Q_{\xi}$ respectively. Indices $\mathrm{i}, \mathrm{j}$, and $\mathrm{k}$ denote Cartesian coordinates. The sum in Eq. (7) extends over all normal modes of vibration.

In the present study, the vibrational contributions are evaluated using the double harmonic model. All calculations were performed with the quantum chemical program package Gaussian 09 [41]. The data analyses were performed with Gauss View 5.08 [42]. In order to find the optimized molecular geometry, the DFT/CAM-B3LYP [43] level geometry optimization were performed with the $6-311++G^{* *}$ basis set. No imaginary frequencies were obtained in vibrational frequencies calculation and thus confirm the equilibrium geometries that correspond to energy minima. Our results are checked with experimental results where available. Electronic and vibrational polarizability, electronic and vibrational contributions to first hyperpolarizability computations are carried out at a variety of DFT level [44, 45]. We investigate the traditional B3LYP $[46,47]$ and PBE [48] functional as well as the long-range corrected CAM-B3LYP, LCBLYP [49] and wB97XD [50] functional, it is now well recognized that the electron correlation (EC) may strongly influence the values of electronic and vibrational contributions to hyperpolarizabilities [51-55].

\section{RESULTS AND DISCUSSION}

\subsection{Structural Data}

All structural results obtained for the systems under study, at HF, PBE and CAM-B3LYP levels of theory with the same basis sets $6-31 G^{*}$ and $6-31++G^{*}$ are illustrated in Table 1.

The $\mathrm{PN}$ bond in $\left(\mathrm{PNH}_{2}\right)_{3}$ is $1.608 \AA$ at $\mathrm{CAM}$ $B 3 L Y P / 6-31++G^{*}, 1.630 \AA$ at $P B E / 6-31++G^{*}$ and $1.595 \AA$ at $H F / 6-31++G^{*}$. This bond is shorter than the one in the $\mathrm{NH}_{2}-\mathrm{PO}_{3}^{-2}$ ion (1.77 $\AA$ ) which corresponds to a simple PN bond [56]. Sabzyan et al. have reported the same results of $P N$ bonds with $1.615 \AA$ at DFT/B3PW91 and $1.618 \AA$ at DFT/B3LYP calculation with the same basis set [57]. There are differences in the crystal data reported in the literature; the PN bond lengths vary from $1.48 \AA$ to $1.58 \AA$ [58]. These variations may be attributed to packing effects and uncertainty in the X-ray diffraction measurements.

The obtained results shown in Table 1 for $\left(\mathrm{PNH}_{2}\right)_{3}$ at PBE level agree with those of CAM-B3LYP with errors varying between $0.02 \AA$ and $0.021 \AA$ with the same basis sets $6-31 \mathrm{~g}^{*}$ and $6-31 \mathrm{~g}++^{*}$.

The PN bond length in HF level as compared to DFT level $(1.594 \AA, 1.629 \AA)$ because the HF level which does not take into account the electronic correlation. With maximum size $0.001 \AA$ to $0.002 \AA$; diffused basis set have negligible effects on the optimized structural parameters, but there is enormous effect of improper (not sufficiently large) basis set on the optimized values of structural parameters obtained for $\left(\mathrm{PNH}_{2}\right)_{3}$ compounds using DFT with the functional PBE and CAM-B3LYP.

In this series of cyclic phosphazenes $\left(\mathrm{NPX}_{2}\right)_{3}$ with $\mathrm{X}$ $=\mathrm{H}, \mathrm{Br}, \mathrm{Cl}$ and $\mathrm{F}$, all identical $\mathrm{PN}$ bonds lengths obtained is a sign of aromaticity in this compounds. 
Table 1: Structural Data of Cyclic Phosphazenes $\left(\mathrm{NPX}_{2}\right)_{n}(\mathrm{n}=3 ; \mathrm{X}=\mathrm{H}, \mathrm{F}, \mathrm{Cl}$ and $\mathrm{Br}$ ) from HF, PBE and CAM-B3LYP Calculations Used 6-31 ${ }^{*}$ and 6-31++g* Basis Sets; Comparison with Semiempirical and Experimental Result

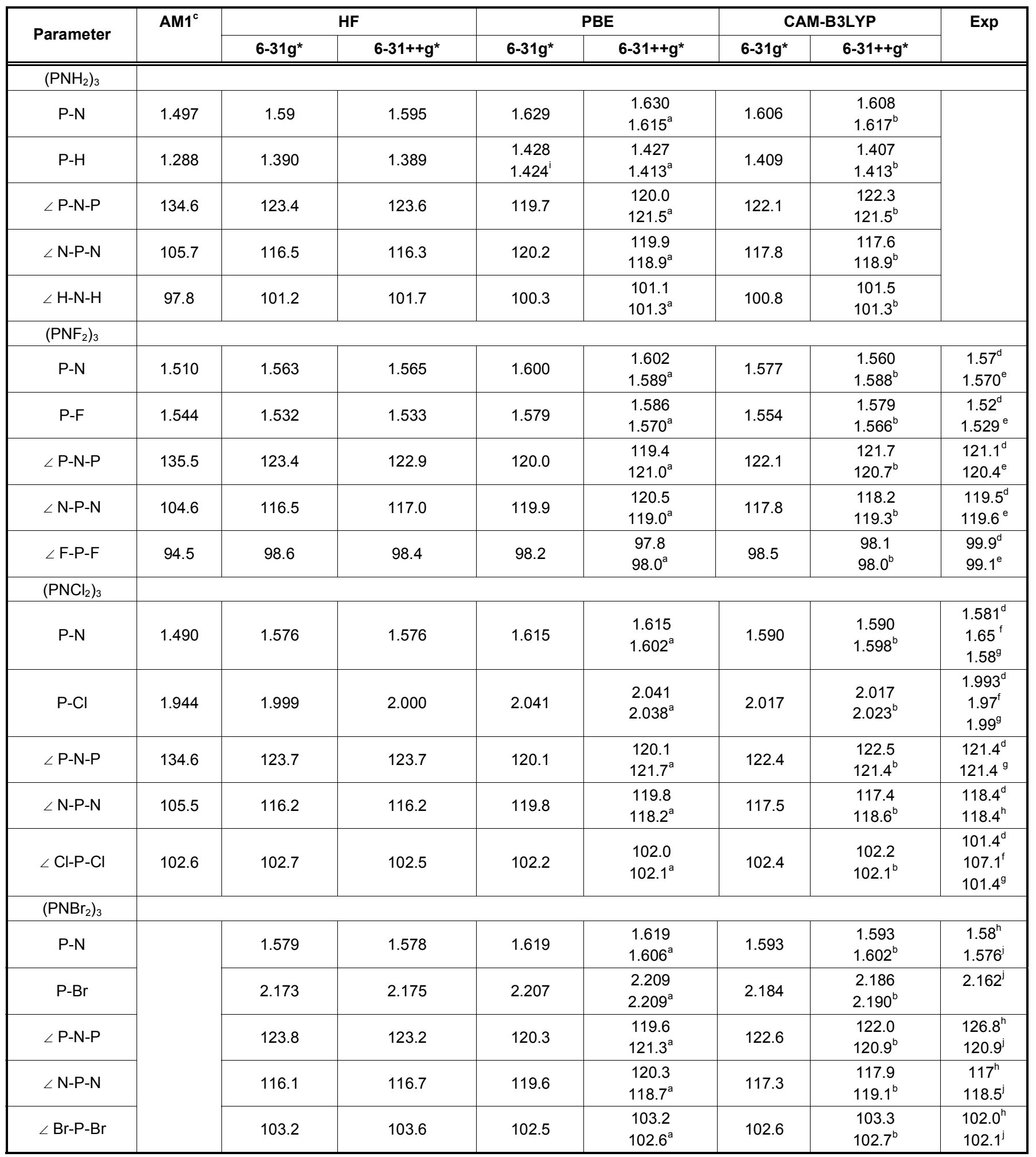

a,b $[57]$ B3PW91and B3LYP calculation.

c[62] AM1 calculation

${ }^{\mathrm{d}}[75] \mathrm{X}$ ray data.

${ }^{\mathrm{e}}[76]$ Electron diffraction

$\mathrm{f}[71]$ Electron diffraction

${ }^{9}[72] \mathrm{X}$ ray data.

h $[73,74] X$ ray data.

[60] B3LYP/6-31++G* for linear phosphazene.

[77] $\mathrm{X}$ ray data. 
Used Quantum chemical calculations in order to find the effect of substitution halogens atoms in PN bonds; Abdellatif et al. [60] have reported that the PN bond lengths in short linear phosphazenes decrease with increasing the electronegativity of $\left(\mathrm{R}_{3} \mathrm{PNH}, \mathrm{R}_{3} \mathrm{PNF}\right.$ and $\mathrm{R}_{3} \mathrm{PNOH}$ with $\mathrm{R}=\mathrm{H}, \mathrm{F}$ ). Sabzyan et al. have reported that the PN bond lengths in the cyclic phosphazenes decrease with increasing the electronegativity of the halogen substituent on the phosphorus atom [57]. Our calculation led to the following results: the $P N$ bond is $1.608 \AA$ in $\left(\mathrm{PNH}_{2}\right)_{3}, 1.593 \AA$ in $\left(\mathrm{PNBr}_{2}\right)_{3}, 1.590 \AA$ in $\left(\mathrm{PNCl}_{2}\right)_{3}$, and $1.560 \AA$ in $\left(\mathrm{PNF}_{2}\right)_{3}$ used the CAMB3LYP/ $6-31++G^{*}$ calculation; so similar results are obtained in this work.

In 1998, Sun used the COMPASS force field (condensed-phase optimized ab initio force field) [59] with $a b$ initio RHF and density functional methods used, 6-31G* basis sets, showed the PN and PX bond lengths and $\angle \mathrm{X}-\mathrm{N}-\mathrm{X}$ angle in cyclic phosphazenes are shortened with increasing the electronegativity of the halogen atom substituted on the phosphorus atom.
The $\angle \mathrm{P}-\mathrm{N}-\mathrm{P}$ angle in $\left(\mathrm{PNH}_{2}\right)_{3}$ is $122.3^{\circ}$ at CAMB3LYP/6-31++ $\mathrm{G}^{*}, 120.0^{\circ}$ at $\mathrm{PBE} / 6-31++\mathrm{G}^{*}$ and $121.7^{\circ}$ at $H F / 6-31++G^{*}$, when the hydrogen atom is substituted with the halogens atoms $\mathrm{Br}, \mathrm{Cl}$ and $\mathrm{F}$, the $\angle$ $\mathrm{P}-\mathrm{N}-\mathrm{P}$ angle at CAM-B3LYP with the same basis set is $122.0^{\circ}, 122.5^{\circ}$ and $121.7^{\circ}$ respectively, so the Fluor atom was important effect on the $\angle \mathrm{P}-\mathrm{N}-\mathrm{P}$ angle.

Trinquier using a standard $a b$ initio method with the DZP basis set [61] in order to find stability and bonding in cyclotriphosphazene, Castro et al. [62] in 2002 used the semi empirical approach AM1 [63] and PM3 [64] to determine these structural properties, also, employing quantum computational, Sabzyan et al. in 2003 [57] are reported molecular structure and bonding, thermochemical stability, vibrational and NMR spectra of cyclic phosphazenes $\left(\mathrm{NPX}_{2}\right)_{3}$, theses results of structural investigation show that all of these phosphazenes have planar structures. The remarkable discrepancies among theoretical values and available experimental data do not allow to state definite conclusions.

Table 2: Comparison of Diagonal Electronic and Vibrational Contributions to Static Polarizability Evaluated Atvarious Levels of Theory. Basis Set: 6-311++G**. The Values are Given in Atomic Units

\begin{tabular}{|c|c|c|c|c|c|c|c|c|}
\hline & & \multicolumn{3}{|c|}{ Vibrational } & \multicolumn{3}{|c|}{ Electronic } & \multirow{2}{*}{$\alpha_{x x}^{e} / \alpha_{x x}^{v}$} \\
\hline & & $\alpha_{x x}^{v}$ & $\alpha_{y y}^{v}$ & $\alpha_{z z}^{v}$ & $\alpha_{\mathrm{xx}}^{\mathrm{e}}$ & $\alpha_{y y}^{\mathrm{e}}$ & $\alpha_{z z}^{\mathrm{e}}$ & \\
\hline \multirow{6}{*}{$\left(\mathrm{PNH}_{2}\right)_{3}$} & $\mathrm{HF}$ & 63.75 & 63.71 & 31.56 & 68.44 & 68.43 & 51.90 & 1.07 \\
\hline & PBE & 30.36 & 30.34 & 34.99 & 76.87 & 76.86 & 54.69 & 2.53 \\
\hline & B3LYP & 30.35 & 30.33 & 43.90 & 76.77 & 76.76 & 54.58 & 2.52 \\
\hline & CAM-B3LYP & 30.26 & 30.24 & 33.64 & 76.62 & 76.62 & 54.28 & 2.53 \\
\hline & LC-BLYP & 29.11 & 29.08 & 31.90 & 75.11 & 75.11 & 53.75 & 2.58 \\
\hline & wB97XD & 28.97 & 28.97 & 30.78 & 74.00 & 74.02 & 52.87 & 2.55 \\
\hline \multirow{6}{*}{$\left(\mathrm{PNBr}_{2}\right)_{3}$} & $\mathrm{HF}$ & 70.11 & 79.22 & 79.30 & 80.25 & 64.32 & 64.21 & 1.14 \\
\hline & PBE & 44.72 & 58.70 & 58.70 & 191.66 & 177.47 & 177.46 & 4.28 \\
\hline & B3LYP & 44.62 & 58.59 & 58.59 & 191.52 & 177.32 & 177.34 & 4.92 \\
\hline & CAM-B3LYP & 44.01 & 58.46 & 58.42 & 190.64 & 175.94 & 177.01 & 4.33 \\
\hline & LC-BLYP & 43.23 & 57.37 & 57.36 & 190.00 & 174.11 & 176.43 & 4.39 \\
\hline & wB97XD & 42.87 & 56.32 & 56.32 & 189.44 & 174.08 & 175.77 & 4.41 \\
\hline \multirow{6}{*}{$\left(\mathrm{PNCl}_{2}\right)_{3}$} & $\mathrm{HF}$ & 55.22 & 65.32 & 67.98 & 123.70 & 115.04 & 115.04 & 2.24 \\
\hline & PBE & 43.01 & 56.98 & 57.05 & 134.09 & 131.05 & 131.58 & 3.11 \\
\hline & B3LYP & 42.89 & 56.88 & 56.89 & 134.00 & 130.88 & 131.44 & 3.12 \\
\hline & CAM-B3LYP & 42.55 & 56.88 & 56.86 & 133.97 & 130.74 & 130.74 & 3.14 \\
\hline & LC-BLYP & 41.87 & 55.56 & 55.56 & 132.65 & 130.00 & 130.01 & 3.16 \\
\hline & wB97XD & 40.98 & 54.89 & 54.87 & 132.01 & 129.13 & 129.16 & 3.22 \\
\hline \multirow{6}{*}{$\left(\mathrm{PNF}_{2}\right)_{3}$} & $\mathrm{HF}$ & 44.01 & 43.99 & 26.47 & 59.27 & 59.26 & 43.75 & 1.34 \\
\hline & PBE & 33.22 & 30.14 & 18.22 & 75.25 & 75.22 & 69.14 & 2.26 \\
\hline & B3LYP & 33.12 & 30.01 & 18.11 & 75.12 & 75.09 & 69.01 & 2.26 \\
\hline & CAM-B3LYP & 32.29 & 31.32 & 19.32 & 74.25 & 74.00 & 68.04 & 2.29 \\
\hline & LC-BLYP & 31.78 & 30.60 & 18.45 & 73.22 & 73.33 & 67.65 & 2.30 \\
\hline & wB97XD & 30.45 & 30.01 & 18.01 & 72.21 & 72.87 & 66.11 & 2.37 \\
\hline
\end{tabular}


It is apparent that our calculation at DFT is agreed with the experimental (X-ray) data and other theoretical study such as Breza et al. [65] and Sabzyan et al. [57] for this cyclic phosphazenes, and better agreement between the calculated results CAM-B3LYP and the Xray data for the chloro-substituted cyclo-phosphazenes. The usual $D_{3}$ h symmetry planar arrangement of the $\left(\mathrm{NPX}_{2}\right)_{3}$ represents a stable structure at all levels of theory. Schulz et al. found the same results of the cyclic phosphazene $\left(\mathrm{NPCl}_{2}\right)$ [66]. It should be noted, that the computed values refer to the gas phase whereas the experimental data refer to the solid state, which always results in small deviations due to lattice effects [67].

\subsection{Electronic and Vibrational Polarizability, Mean Polarizability and Polarizability Anisotropy}

The systems that are the subject of the present investigation are given in (Figure 1). The results presented in Table 2 are the essential basis for the further discussion on the effect of electronic and vibrational contributions to nonlinear optical properties.

The results shown in Table 2, Figures 2 and $\mathbf{3}$ presents electronic and vibrational contributions to static polarizability for all investigated compounds, the values of the polarizabilities ( $\alpha$ ) of Gaussian 09 output are reported in atomic units (au).

Used the traditional B3LYP and PBE functionals and the long-range corrected functional like Coulomb- attenuating method CAM-B3LYP, LC-BLYP and wB97XD introduces a part of electron correlation through the use of an exchange correlation term in the energy expression, with small additional cost in the computational procedure and compared to $\mathrm{HF}$ observed for standard methods. The calculations show that the substitution effect of electronic correlation on a value is observed solely for the electronic counterpart; the change in the vibrational contributions to polarizability upon inclusion of electronic correlation is significant. The obtained DFT results are virtually unaffected by the change of the traditional functional PBE and B3LYP and with small error with the longrange corrected functional CAM-B3LYP, LC-BLYP and wB97XD.

The ratio between the vibrational and electronic contributions $\alpha_{x x}^{v} / \alpha_{x x}^{e}$ might depend crucially on the applied level of theory; these results are confirmed by Sucarrat et al. [68] and other studies for conjugated organic molecules [69].

The mean polarizability was calculated from the polarizability components as [70]:

$\langle\alpha\rangle=\frac{1}{3}\left(\alpha_{x x}+\alpha_{y y}+\alpha_{z z}\right)$

And the polarizability anisotropy as:

$$
|\Delta \alpha|=\sqrt{\frac{1}{2}\left[\left(\left(\alpha_{x x}-\alpha_{y y}\right)^{2}+\left(\alpha_{x x}-\alpha_{z z}\right)^{2}+\left(\alpha_{y y}-\alpha_{z z}\right)^{2}\right)\right]}
$$

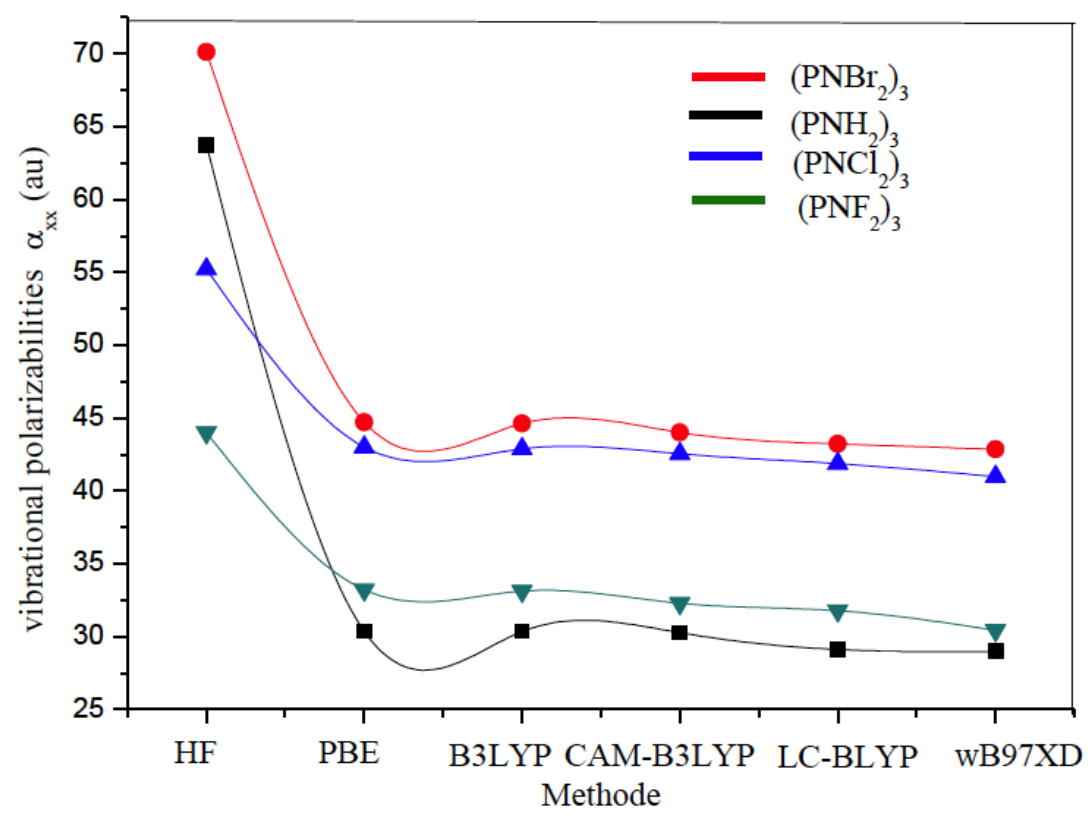

Figure 2: Vibrational contributions to static polarizability $\alpha_{x x}^{v}$ evaluated at various levels of theory used $6-311++G^{* *}$ basis set. The values are given in atomic units. 


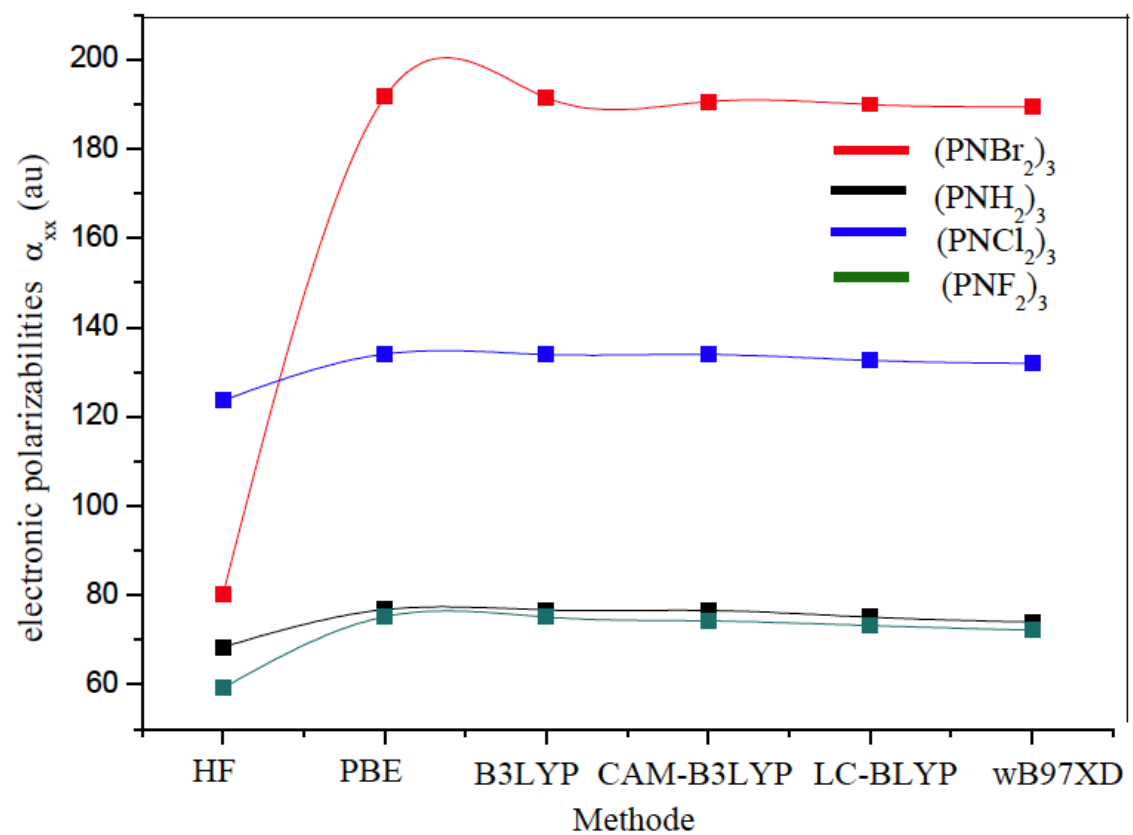

Figure 3: Electronic contributions to static polarizability $\alpha_{x x}^{e}$ evaluated at various levels of theory used $6-311++G * *$ basis set. The values are given in atomic units.

Table 3: Basis Set Effects on PBE Vibrational Polarizability Responses, the Mean Polarizability and The polarizability Anisotropy of $\left(\mathrm{PNF}_{2}\right)_{3}$. The $(\alpha)$ Values are given in Atomic Units $\left(1 \mathrm{a} \cdot \mathrm{u}=1.6488 \times 10^{-41} \mathrm{C}^{2} \mathrm{~m}^{2} \mathrm{~J}^{-1}=0.14818 \AA^{3}\right)$

\begin{tabular}{|c|c|c|c|c|c|}
\hline Basis set & $\alpha_{x x}^{v}$ & $\alpha_{y y}^{v}$ & $\alpha_{z z}^{v}$ & $\langle\alpha\rangle$ & $|\Delta \alpha|$ \\
\hline $6-31 G$ & 83.64 & 83.04 & 40.62 & 69.1 & 42.72 \\
\hline $6-31 G^{*}$ & 39.79 & 39.79 & 22.93 & 34.17 & 16.85 \\
\hline $6-31+G$ & 72.71 & 72.52 & 42.65 & 62.62 & 29.96 \\
\hline $6-31+G^{*}$ & 41.59 & 41.59 & 24.30 & 35.82 & 17.29 \\
\hline $6-311 G$ & 62.12 & 61.97 & 35.30 & 53.13 & 26.74 \\
\hline $6-311 G^{*}$ & 43.60 & 43.57 & 25.97 & 37.71 & 17.61 \\
\hline $6-311+G^{*}$ & 43.42 & 43.39 & 25.66 & 37.49 & 17.73 \\
\hline cc-pVDZ & 44.01 & 44.62 & 26.27 & 38.04 & 18.25 \\
\hline cc-pVTZ & 44.26 & 44.92 & 26.87 & 38.45 & 19.00 \\
\hline Aug-cc-pVDZ & 45.11 & 45.17 & 27.05 & 38.87 & 19.22 \\
\hline
\end{tabular}

In Table $\mathbf{3}$ and Figure $\mathbf{4}$, the polarizability components, mean polarizability and the polarizability anisotropy have been presented.

To avoid possible systematic errors in the computation of the linear optical properties, we used two basis set families of different construction as implemented in GAUSSIAN 09. The first family comprises the correlation consistent cc-pVDZ, aug-ccpVDZ, and cc-pVTZ basis sets, and the second one is built upon the 6-31G and 6-311G substrates, by systematically adding standard diffuse and polarization Gaussian type functions. All geometries were optimized before calculation of vibrational contributions to polarizability response $\alpha_{\mathrm{xx}}, \alpha_{\mathrm{yy}}$ and $\alpha_{\mathrm{zz}}$ mean polarizability $\langle\alpha\rangle$ and the polarizability anisotropy $|\Delta \alpha|$. We examined the basis set effects at PBE levels that are the least computationally demanding among the DFT levels we used.

Depending on the basis set choice, the mean polarizability varies from 69.1 (6-31G basis set) to 37.49 au $\left(6-311++G^{*}\right)$ at the same PBE level. These sorts of variations reveal a rather small and larger basis set effect on this property. No dramatic changes on the computed values of mean polarizability and the polarizability anisotropy $|\Delta \alpha|$ are noted if we used the 


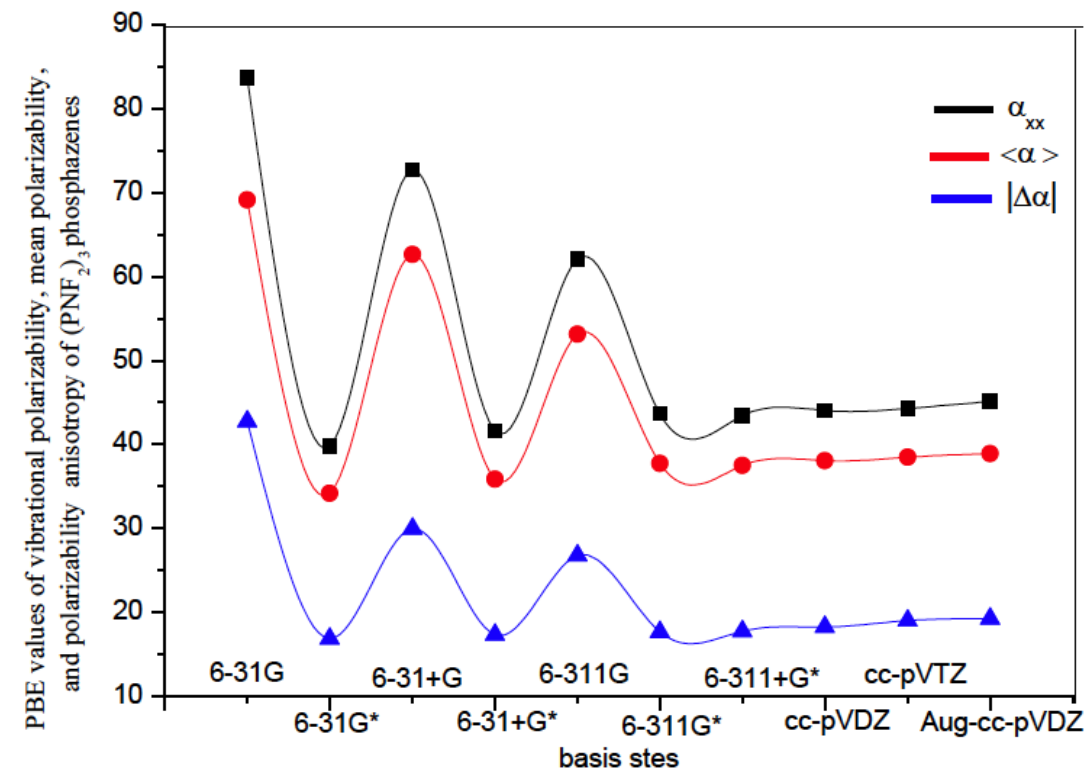

Figure 4: Basis set effects on PBE vibrational polarizability responses, the mean polarizability and the polarizability anisotropy of $\left(\mathrm{PNF}_{2}\right)_{3}$ phosphazenes. The $(\alpha)$ values are given in atomic units.

correlation consistent cc-pVDZ, aug-cc-pVDZ, and ccpVTZ basis sets.

The results shows that for all properties; there is a good correlation between the largest extension basis sets like 6-311G*, 6-311+G*, cc-pVDZ, cc-pVTZ and Aug-cc-pVDZ. The addition of p-polarization functions tends to increase in the $\langle\alpha\rangle$ mean polarizability, and the same statement for the polarizability anisotropy. Going from double- $\zeta$ to a triple- $\zeta$ leads to smaller increase in all properties.

\subsection{Dipole Moment, Electronic and Vibrational Contributions to First Hyperpolarizability}

Table 4 summarizes dipole moment, electronic and vibrational contributions to first-order hyperpolarizability calculated at HF, PBE, B3LYP, CAM-B3LYP, LCBLYP, and wB97XD levels for the geometry optimized at the CAM-B3LYP/6-311++G $(d, p)$ level of theory. The results shows that when passing from traditional functional PBE and B3LYP to long-range corrected functional CAM-B3LYP, LC-BLYP and wB97XD calculation of electronic and vibrational contribution to first hyperpolarizabilities, only marginal effects are observed. In fact, the high symmetry of all structures $\left(\mathrm{PNH}_{2}\right)_{3},\left(\mathrm{PNBr}_{2}\right)_{3},\left(\mathrm{PNCl}_{2}\right)_{3}$ and $\left(\mathrm{PNF}_{2}\right)_{3}$, which present a planar cyclic arrangement, with rather small deviations from perfect planarity. This property is clearly revealed by the zero or nearly null dipole moment and null first hyperpolarizabilities calculated at ab initio (HF) and DFT levels for all the molecules.

\section{CONCLUSIONS}

In this study, we investigate structural data, ab initio, and DFT calculation of electronic and vibrational contribution to polarizabilities, the mean polarizability, the polarizability anisotropy, electronic and vibrational contributions to first hyperpolarizabilities of cyclic phosphazenes $\left(\mathrm{PNX}_{2}\right)_{3}$ with $\mathrm{n}=3$ and $\mathrm{X}=\mathrm{H}, \mathrm{Br}, \mathrm{Cl}$ and $F$. We showed that, these numerical simulations obtaining reliable information on the geometrical structure and the substitution effect on the electronic and vibrational nonlinear optical NLO properties. In this series of cyclic phosphazenes $\left(\mathrm{NPX}_{2}\right)_{3}$ with $\mathrm{X}=\mathrm{H}, \mathrm{Br}$, $\mathrm{Cl}$ and $\mathrm{F}$, all identical $\mathrm{PN}$ bonds lengths obtained is a sign of aromaticity in this compounds. The obtained structural data results in this paper agree with other theoretical calculation, and experimental data.

This study for this cyclic phosphazenes compounds $\left(\mathrm{NPX}_{2}\right)_{3}$ on the basis set effect and the inclusion of electron correlation, by going from the Hartree-Fock to the DFT (PBE, B3LYP, CAM-B3LYP, LC-BLYP, and WB97XD levels), leads to largest variations of vibrational and electronic contributions to polarizability. Only marginal effects are observed when passing from the traditional functional PBE and B3LYP to long-range corrected functional CAM-B3LYP, LC-BLYP and wB97XD for calculation of linear and nonlinear optical properties of this cyclic phosphazenes.

We present an accurate investigation of the NLO properties of a series of phosphazene, focusing on the relationships between dipole moment, first 
Table 4: Dipole Moment (D), Electronic and Vibrational Contributions to First-Order Hyperpolarizability Calculated for the Geometry Optimized at the CAM-B3LYP/6-311++G (d, p) Level of Theory. The Values are Given in Atomic Units

\begin{tabular}{|c|c|c|c|c|c|c|c|c|}
\hline & & \multirow{2}{*}{$\begin{array}{l}\text { Dipole } \\
\text { moment }\end{array}$} & \multicolumn{3}{|c|}{$\beta$ Vibrational } & \multicolumn{3}{|c|}{$\beta$ Electronic } \\
\hline & & & $\beta_{\mathrm{xxx}}^{\mathrm{v}}$ & $\beta_{y y y}^{v}$ & $\beta_{z z z}^{v}$ & $\beta_{\mathrm{xxx}}^{\mathrm{e}}$ & $\beta_{y y y}^{\mathrm{e}}$ & $\beta_{z z z}^{\mathrm{e}}$ \\
\hline \multirow{6}{*}{$\left(\mathrm{PNH}_{2}\right)_{3}$} & $\mathrm{HF}$ & 0.001 & 0.05 & 0.05 & 0.05 & 0.01 & 0.01 & 0.01 \\
\hline & PBE & 0.000 & 0.03 & 0.03 & 0.03 & 0.03 & 0.01 & 0.01 \\
\hline & B3LYP & 0.001 & 0.00 & 0.00 & 0.00 & 0.00 & 0.00 & 0.01 \\
\hline & CAM-B3LYP & 0.000 & 0.03 & 0.03 & 0.03 & 0.03 & 0.01 & 0.01 \\
\hline & LC-BLYP & 0.001 & 0.02 & 0.02 & 0.02 & 0.02 & 0.01 & 0.00 \\
\hline & wB97XD & 0.001 & 0.01 & 0.01 & 0.01 & 0.01 & 0.01 & 0.00 \\
\hline \multirow{6}{*}{$\left(\mathrm{PNBr}_{2}\right)_{3}$} & $\mathrm{HF}$ & 0.001 & 0.01 & 0.05 & 0.00 & 0.01 & 0.00 & .000 \\
\hline & PBE & 0.000 & 0.03 & 0.03 & 0.00 & 0.03 & 0.01 & 0.01 \\
\hline & B3LYP & 0.001 & 0.02 & 0.00 & 0.00 & 0.00 & 0.01 & 0.01 \\
\hline & CAM-B3LYP & 0.000 & 0.03 & 0.03 & 0.00 & 0.03 & 0.01 & 0.01 \\
\hline & LC-BLYP & 0.000 & 0.02 & 0.02 & 0.00 & 0.02 & 0.00 & 0.00 \\
\hline & wB97XD & 0.001 & 0.01 & 0.01 & 0.00 & 0.01 & 0.00 & 0.00 \\
\hline \multirow{6}{*}{$\left(\mathrm{PNCl}_{2}\right)_{3}$} & $\mathrm{HF}$ & 0.001 & 0.00 & 0.01 & 0.00 & 0.01 & 0.00 & 0.00 \\
\hline & PBE & 0.000 & 0.04 & 0.03 & 0.03 & 0.03 & 0.00 & 0.00 \\
\hline & B3LYP & 0.000 & 0.02 & 0.00 & 0.02 & 0.00 & 0.00 & 0.00 \\
\hline & CAM-B3LYP & 0.001 & 0.01 & 0.03 & 0.00 & 0.03 & 0.00 & 0.00 \\
\hline & LC-BLYP & 0.001 & 0.00 & 0.02 & 0.00 & 0.02 & 0.00 & 0.00 \\
\hline & wB97XD & 0.001 & 0.00 & 0.01 & 0.00 & 0.00 & 0.00 & 0.0 \\
\hline \multirow{6}{*}{$\left(\mathrm{PNF}_{2}\right)_{3}$} & $\mathrm{HF}$ & 0.001 & 0.02 & 0.01 & 0.02 & 0.01 & 0.02 & 0.00 \\
\hline & PBE & 0.000 & 0.01 & 0.03 & 0.01 & 0.02 & 0.02 & 0.00 \\
\hline & B3LYP & 0.001 & 0.01 & 0.00 & 0.01 & 0.00 & 0.01 & 0.00 \\
\hline & CAM-B3LYP & 0.000 & 0.01 & 0.03 & 0.01 & 0.03 & 0.03 & 0.00 \\
\hline & LC-BLYP & 0.000 & 0.00 & 0.02 & 0.00 & 0.02 & 0.02 & 0.00 \\
\hline & wB97XD & 0.000 & 0.00 & 0.01 & 0.00 & 0.00 & 0.00 & 0.00 \\
\hline
\end{tabular}

hyperpolarizabilities and the symmetry of the molecules. In this case, symmetric planar structures obtained for the whole cyclic phosphazenes, they all have null dipole moments and null first hyperpolarizabilities calculated at $a b$ initio (HF) and DFT levels.

\section{REFERENCES}

[1] Liebig J. Nachtrag der Redaction. Ann Pharm 1834; 11: 12939.

\section{http://dx.doi.org/10.1002/jlac.18340110202}

[2] Gladstone JH, Holmes JD. Onchlorophosphuret of nitrogen, and its products of decomposition. J Chem Soc 1864; 17 : 225-37.

http://dx.doi.org/10.1039/JS8641700225

[3] Stokes HN. Ueber Chlorphmphorstickstoff und zweiseiner homologen Verbindungen, Ber. Dtsch Chem Ges 1895; 28 : 437 http://dx.doi.org/10.1002/cber.189502801106

[4] Lee SB, Song SC, Jin J, Sohn YS, Thermosensitive Cyclotriphosphazenes. J Am Chem Soc 2000; 122: 83158316.

http://dx.doi.org/10.1021/ja001542j
[5] Carriedo GA, Alonso FJG, Garcia JL, Carbajo RJ, Ortiz FL. Eur J Inorg Chem 1999; 6: 1015-1020. http://dx.doi.org/10.1002/(SICI)15213765(19980807)4:8<1489::AID-CHEM1489>3.0.CO;2-Q

[6] Lieu PJ, Magill JH, Alarie YC. J Fire and Flammability 1980; 11: 167.

[7] Olshavsky MA, Allcock HR. Polyphosphazenes with high refractive-indexes synthesis, characterization, and opticalproperties. Macromolecules 1995; 28: 6188-6197. http://dx.doi.org/10.1021/ma00122a028

[8] Allcock HR, Dembek AA, Kim C, Devine RLS, Shi Y, Steier WH, Spangler CW. Second-order nonlinear optical poly(organophosphazenes): synthesis and nonlinear optical characterization. Macromolecules 1991; 24: 1000-1010. http://dx.doi.org/10.1021/ma00005a006

[9] Allcock HR, Richard, Fitzpatrick J, Salvati L. Sulfonation of (aryloxy) and (arylamino)phosphazenes: small-molecule compounds, polymers, and surfaces. Chem Mater 1991; 3: $1120-1132$. http://dx.doi.org/10.1021/cm00018a032

[10] Allcock HR, Kim C. Photochromic polyphosphazeneswith spiropyran units. Macromolecules 1991; 24: 2846-2851. http://dx.doi.org/10.1021/ma00010a032

[11] Bortolus P, Gleria M. J Inorg Organomet Polym 1994; 4: 1-236.

[12] Diaz C, Spodine E, Moreno Y, Carrasco E. A one step functionalization, coordination of $\mathrm{N}_{3} \mathrm{P}_{3} \mathrm{Cl}_{6}$. J Chil Chem Soc 2004; 49: 205-207. http://dx.doi.org/10.4067/S0717-97072004000300002 
[13] Diaz C, Valenzuela ML, Spodine E, Moreno Y, Peña O. A cyclic and polymeric phosphazene as solid state template for the formation of $\mathrm{RuO}_{2}$ nanoparticles. J Cluster Science 2007; 18: $831-844$

http://dx.doi.org/10.1007/s10876-007-0132-y

[14] Gates DP, McWilliams AR, Ziembinski R, Liable-Sands LM, Guzei IA, Glenn Yap PA, Rheingold AL, Manners I. Chemistry of Boratophosphazenes. Chem Eur J 1998; 4: 1489-1503.

http://dx.doi.org/10.1002/(SICI)1521-

3765(19980807)4:8<1489::AID-CHEM1489>3.0.CO;2-Q

[15] Hartree DR. The wave mechanics of an atom with a nonCoulomb central field. Part II. Some results and discussion. Proc Cambridge Phil Soc 1928; 24: 111-132.

[16] Fock V. Näherungsmethodezur Losung des quanten-mechanischen Mehrkörperprobleme. Z Phys 1930; 61: 126-148. http://dx.doi.org/10.1007/BF01340294

[17] Hohenberg P, Kohn W. Inhomogeneous Electron Gas. Phys Rev 1964; 136: B864.

http://dx.doi.org/10.1103/PhysRev.136.B864

[18] Møller Ch, Plesset MS. Note on an Approximation Treatment for Many-Electron Systems. Phys Rev 1934; 46: 618. http://dx.doi.org/10.1103/PhysRev.46.618

[19] Kirtman B, Champagne B, Luis JM. Efficient treatment of the effect of vibrations on electrical, magnetic, and spectroscopic properties. J Comput Chem 2000; 21: 1572-1588 http://dx.doi.org/10.1002/1096987X(200012)21:16<1572::AID-JCC14>3.0.CO;2-8

[20] Kurtz H, Stewart J, Dieter KM. Calculation of the nonlinear optical properties of molecules. J Comput Chem 1990; 11: 82-87.

http://dx.doi.org/10.1002/jcc.540110110

[21] Dudis DS, Kurtz HA, Lipkowitz KB, Boyd DB. Reviews in Computational Chemistry, Wiley-VCH, Weinheim 1998; 12: 241-279.

http://dx.doi.org/10.1002/9780470125892.ch5

[22] Pluta T, Kolaski M, Medved M, Budzák S. Chem Phys Lett 2012; 546: 24-29.

http://dx.doi.org/10.1016/j.cplett.2012.07.032

[23] Sekino H, Maeda Y, Kamiya M, Hirao K. Polarizability and second hyperpolarizability evaluation of long molecules by the density functional theory with long-range correction. J Chem Phys 2007; 126: 014107.

http://dx.doi.org/10.1063/1.2428291

[24] Jacquemin D, Perpete EA, Scalmani G, Frisch MJ, Kobayashi R, Adamo C. J Chem Phys 2007; 126: 144105144112 http://dx.doi.org/10.1063/1.2715573

[25] Kirtman B, Bonness S, Solis AR, Champagne B, Matsumoto $H$, Sekino $H$. Calculation of electric dipole (hyper)polarizabilities by long-range-correction scheme in density functional theory: A systematic assessment for polydiacetylene and polybutatriene oligomers. J Chem Phys 2008; 128: 114108

http://dx.doi.org/10.1063/1.2885051

[26] Song JW, Watson MA, Sekino H, Hirao K. Nonlinear optical property calculations of polyynes with long-range corrected hybrid exchange-correlation functionals. J Chem Phys 2008; 129: 024117.

http://dx.doi.org/10.1063/1.2936830

[27] Limacher PA, Mikkelsen KV, Luthi HP. On the accurate calculation of polarizabilities and second hyperpolarizabilities of polyacetylene oligomer chains using the CAM-B3LYP density functional. J Chem Phys 2009; 130: 194114. http://dx.doi.org/10.1063/1.3139023

[28] Alparone A. Comparative study of $\operatorname{CCSD(T)}$ and DFT methods: Electronic (hyper)polarizabilities of glycine. Chem Phys Lett 2011; 514: 21. http://dx.doi.org/10.1016/j.cplett.2011.08.010
[29] Alparone A. Structural, energetic and response electric properties of cyclic selenium clusters: an ab initio and density functional theory study. Theor Chem Acc 2012; 131: 1239. http://dx.doi.org/10.1007/s00214-012-1239-2

[30] Loboda O, Zalesny R, Avramopoulos A, Luis JM, Kirtman B Tagmatarchis N, Reis H, Papadopoulos MG. Linear and Nonlinear Optical Properties of [60] Fullerene Derivatives. J Phys Chem A 2009; 113: 1159-1170. http://dx.doi.org/10.1021/jp808234x

[31] Bishop D, Norman $P$, Calculations of dynamic hyperpolarizabilities for small and medium sized molecules: Handbook of Advanced Electronic and Photonic Materials and Devices, Academic Press, San Diego.9. 2001.

[32] Medved M, Stachová M, Jacquemin D, André JM, Perpète EA, A generalized Romberg differentiation procedure for calculation of hyperpolarizabilities. J Mol Struct 2007; 847: 39-46. http://dx.doi.org/10.1016/j.theochem.2007.08.028

[33] Bottcher CJF. Theory of Electric Polarization, Elsevier, Amsterdam 1973. http://dx.doi.org/10.1016/0022-2860(74)80080-3

[34] Castiglioni C, Gussoni M, Del Zoppo M, Zerbi G. Relaxation contribution to hyperpolarizability. A semiclassical model. Solid State Comm 1992; 82: 13-17. http://dx.doi.org/10.1016/0038-1098(92)90397-R

[35] Gussoni M, Rui M, Zerbi G. Electronic and relaxation contribution to linear molecular polarizability. An analysis of the experimental values. J Mol Struct 1998; 447: 163-215. http://dx.doi.org/10.1016/S0022-2860(97)00292-5

[36] Bishop DM. Adv Chem Phys 1998; 104: 1-40.

[37] Bishop DM, Kirtman B. A perturbation method for calculating vibrational dynamic dipole polarizabilities and hyperpolarizabilities. J Chem Phy 1991; 95: 2646. http://dx.doi.org/10.1063/1.460917

[38] Kirtman B, Bishop DM. Compact formulas for vibrational dynamic dipole polarizabilities and hyperpolarizabilities. J Chem Phys 1992; 97: 5255.

\section{http://dx.doi.org/10.1063/1.463806}

[39] Orr BJ, Ward JF. Perturbation theory of the non-linear optical polarization of an isolated system. Mol Phys 1971; 20: 513. http://dx.doi.org/10.1080/0026897710010047

[40] Bishop DM, Kirtman B, Champagne B. Differences between the exact sum-over-states and the canonical approximation for the calculation of static and dynamic hyperpolarizabilities. J Chem Phys 1997; 107: 5780. http://dx.doi.org/10.1063/1.474337

[41] Frisch MJ, Trucks GW, Schlegel HB, et al. Gaussian 09, Revision A.02, Gaussian, Inc, Wallingford, CT 2009.

[42] Dennington R, Keith T, Millam J. SemichemInc, Shawnee Mission KS, Gauss View, Version 52009

[43] Yanai T, Tew DP, Handy NC. A new hybrid exchangecorrelation functional using the Coulomb-attenuating method (CAM-B3LYP). Chem Phys Lett 2004; 39: 51-57. http://dx.doi.org/10.1016/j.cplett.2007.05.055

[44] Lee C, Yang W, Parr RG. Development of the Colle-Salvetti correlation-energy formula into a functional of the electron density. Phys Rev 1988; B37: 785

http://dx.doi.org/10.1103/PhysRevB.37.785

[45] Hohenberg P, Kohn W, Inhomogeneous Electron Gas, Phys. Rev 1964; 136: B864. http://dx.doi.org/10.1103/PhysRev.136.B864

[46] Becke AD, Density-functional exchange-energy approximation with correct asymptotic behavior. Phys Rev 1988; A 38: 3098. http://dx.doi.org/10.1103/PhysRevA.38.3098

[47] Lee C, Yang RG. Parr, Phys Rev 1988; B 37: 785-789. http://dx.doi.org/10.1103/PhysRevB.37.785 
[48] Perdew JP, Burke K, Ernzerhof M. Generalized Gradient Approximation Made Simple. Phys Rev Lett 1996; 77: 3865. http://dx.doi.org/10.1103/PhysRevLett.77.3865

[49] likura H, Tsuneda T, Yanai T, Hirao K. Long-range correction scheme for generalized-gradient-approximation exchange functionals. J Chem Phys 2001; 115: 3540- 3544. http://dx.doi.org/10.1063/1.1383587

[50] Chai JD, Head-Gordon M. Long-range corrected hybrid density functionals with damped atom-atom dispersion corrections. Phys Chem Chem Phys 2008; 10: 6615-20. http://dx.doi.org/10.1039/b810189b

[51] Sim F, Chin S, Dupuis M, Rice J. Electron correlation effects in hyperpolarizabilities of p-nitroaniline. J Phys Chem 1993; 97: 1158-1163. http://dx.doi.org/10.1021/j100108a010

[52] Pecul M, Pawłowski F, Jørgensen P, Köhn A, Hättig C. Highorder correlation effects on dynamic hyperpolarizabilities and their geometric derivatives: a comparison with density functional results. J Chem Phys 2006; 124: 114101. http://dx.doi.org/10.1063/1.2173253

[53] Zalesny R, Bartkowiak W, Toman P, Leszczynski J. Computational insight into relations between electronic and vibrational polarizabilities within the two-state valence-bond charge-transfer model. J Chem Phys 2007; 337: 77-80. http://dx.doi.org/10.1016/j.chemphys.2007.06.031

[54] Zalesny R, Wójcik G, Mossakowska I, Bartkowiak W, Avramopoulos A, Papadopoulos MG. Static electronic and vibrational first hyperpolarizability of meta-dinitrobenzene as studied by quantum chemical calculations. J Mol Struct (Theochem) 2009; 901: 46-50.

http://dx.doi.org/10.1016/j.theochem.2009.04.011

[55] Andrea A. Nonlinear optical properties of fluorobenzenes: A Time-Dependent Hartree-Fock study. Computational and Theoretical Chemistry 2013; 1013: 23-24. http://dx.doi.org/10.1016/j.comptc.2013.03.014

[56] Cruiskshank DWJ. Refinements of structures containing bonds between $\mathrm{Si}, \mathrm{P}, \mathrm{S}$ or $\mathrm{Cl}$ and $\mathrm{O}$ or N. I. NaPO3NH3. Acta Crystallogr 1964; 17: 671-672.

http://dx.doi.org/10.1107/S0365110X64001633

[57] Sabzyan H, Kalantar Z. Ab initio RHF and density functional B3LYP and B3PW91 study of (NPF2)n;n=2,3,4 and (NPX2)3; $\mathrm{X}=\mathrm{H}, \mathrm{Cl}, \mathrm{Br}$ cyclic phosphazenes. J Molecul Struct (Theochem) 2003; 663: 149-157.

http://dx.doi.org/10.1016/j.theochem.2003.08.132

[58] Sun H. Molecular Structures and Conformations of Polyphosphazenes-A Study Based on Density Functional Calculations of Oligomers. J Am Chem Soc 1997; 119: 3611. http://dx.doi.org/10.1021/ja963077p

[59] Sun H, Ren P, Fried JR. The COMPASS force field: parameterization and validation for phosphazenes. Comp and Theor Polymer Sci 1998; 8: 229-246. http://dx.doi.org/10.1016/S1089-3156(98)00042-7

[60] Abdellatif ML, Maouche B, Belmiloud Y, Triaki N, Brahimi M. Theoretical Study of the Linear Short-Chain PhosphazeneNa Complexes. The Open Structural Biology Journal 2009; 3: 26-33. http://dx.doi.org/10.2174/1874199100903010026

[61] Trinquier G. Structure, stability, and bonding in cyclodiphosphazene andcyclotriphosphazene. J Am Chem Soc 1986; 108(4): 568-577.

http://dx.doi.org/10.1021/ja00264a002

[62] Mora V, Castro EA. Semiempirical Study of the Molecular Structure of Cyclic (NPX2)nPhosphazenes ( $n=2,3,4,5$ and
$X=H, F, C l)$. Chem Pap 2002; 5: 250-255. Available from www.chempap.org/?id=7\&paper $=602$

[63] Dewar MJS, Zoebisch EG, Healy EF, Stewart JJP. Development and use of quantum mechanical molecular models. 76. AM1: a new general purpose quantum mechanical molecular model. J Am Chem Soc 1985; 107: 3902-3909.

http://dx.doi.org/10.1021/ja00299a024

[64] Stewart JJP, Optimization of parameters for semiempirical methods I. Method. J Comp Chem 1989; 10: 209-220.

http://dx.doi.org/10.1002/jcc.540100208

[65] Breza M, Biskupic S. Ab initio study of simple short-chain phosphazenes. J Mol Structure (Theochem) 1995; 332: 277281.

http://dx.doi.org/10.1016/0166-1280(94)03940-M

[66] Schulz A, Thormählen M, Müller HC. From Substituted Cyclotriphosphazenes to Double-Stranded Phosphazene Chains-A Quantumchemical Study. Internet Electronic Journal of Molecular Design 2003; 2: 653-677. Available from http://biochempress.com/Files/iejmd_2003_2_0653.pdf

[67] Klapötke TM, Schulz A. Ab initio methods in Main Group Chemistry. Wiley: Chichester 1998.

[68] Torrent-Sucarrat M, Sola M, Duran M, Luis JM, Kirtman B. Basis set and electron correlation effects on ab initio electronic and vibrational nonlinear optical properties of conjugated organic molecules. J Chem Phys 2003; 118: 711718.

http://dx.doi.org/10.1063/1.1521725

[69] Zaleśny R, Papadopoulos M, Bartkowiak W, Kaczmarek A On the electron correlation effects on electronic and vibrational hyperpolarizability of merocyanine dyes. J Chem Phys 2008; 129: 134310. http://dx.doi.org/10.1063/1.2985736

[70] Kanis DR, Ranter MA, Marks TJ. Design and construction of molecular assemblies with large second-order optical nonlinearities. Quantum chemical aspects. Chem Rev 1994; 94: 195-242. http://dx.doi.org/10.1021/cr00025a007

[71] Giglio E, Ricerca. Sci, Crystal structure of trimeric phosphonitrile chloride. Refinement of the molecular structure 1960; 30: 721.

[72] Bullen GJ. An improved determination of the crystal structure ofhexachloro-cyclotriphosphazene (phosphonitrilic chloride). J Chem Soc A 1971; 1450-1453. http://dx.doi.org/10.1039/J19710001450

[73] Giglio E, Pompa F, Ripamonti A. Molecular conformation of linear polyphosphonitrile chloride. J Polym Sci 1962; 59: 293300.

http://dx.doi.org/10.1002/pol.1962.1205916807

[74] Giglio E, Puliti R. Crystal structure of trimeric phosphonitrilic bromide. Acta Cristallogr 1967; 22: 304-307.

http://dx.doi.org/10.1107/S0365110X67000519

[75] Allcock HR. Phosphorus-Nitrogen Compounds Cyclic, Linear and High Polymeric Systems Academic Press. New York 1972.

[76] Daugill WM. Phosphonitrilic derivatives. Part X. The crystal structure of trimeric phosphonitrilic fluoride. J Chem Soc 1963; 3211-3217. http://dx.doi.org/10.1039/JR9630003211

[77] Zoer H, Wagner AJ. The crystal structure of compounds with (N-P)nrings. Acta Crystallogr B 1970; 26: 1812-1819. http://dx.doi.org/10.1107/S05677400870004946 